
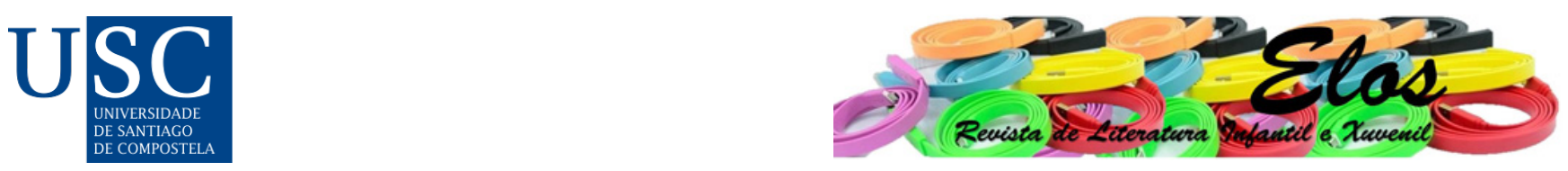

Elos: Revista de Literatura Infantil e Xuvenil, (8), 2021. ISSN-e: 2386-7620

https://doi.org/10.15304/elos.8.7624

Notas

\title{
Labirintos e casas, portas e segredos: análise do espaço nas novelas juvenis de Ana Teresa Pereira
}

\author{
Laberintos y casas, puertas y secretos: análisis del espacio en las novelas \\ juveniles de Ana Teresa Pereira \\ Labyrinths and houses, doors and secrets: analysis of place in the youth novels by \\ Ana Teresa Pereira
}

\author{
Sara Raquel Duarte Reis da Silva ${ }^{1}$ iD \\ ${ }^{1}$ Universidade do Minho, Portugal \\ sara_silva@ie.uminho.pt
}

Recibido: 06/04/2021; Aceptado: 08/09/2021

\section{Resumo}

Procurando situar Ana Teresa Pereira, autora reconhecida/premiada no domínio da literatura dita canónica ou para adultos, no contexto da escrita contemporânea preferencialmente dedicada ao leitor juvenil, procede-se à análise de um conjunto de livros, reunidos sob a designação de "O Labirinto". São cinco obras que integram um "ciclo" desenvolvido em torno da casa. Estas narrativas seguem, no fundamental e em certa medida, uma particular formula fiction celebrizada por colecções como as que Enid Blyton assinou na década de 30 do século XX e que continuam a ser actualmente reeditadas e globalmente comercializadas. As novelas juvenis de Ana Teresa Pereira singularizam-se, porém, não apenas pela forte presença do mistério e da indagação, mas também pela densidade simbólica de certos espaços, como a casa, por exemplo, bem como pelas ressonâncias ou alusões intertextuais/culturais que proporcionam o contacto com autores, excertos textuais, títulos de filmes, entre outros.

Palavras-chave: narrativa juvenil; formula fiction; Ana Teresa Pereira; espaço; casa; simbologia; intertextualidade.

\section{Resumen}

Buscando situar a Ana Teresa Pereira, autora reconocida/premiada en el campo de la denominada literatura canónica o para adultos, en el contexto de la escritura contemporánea preferentemente dedicada al lector juvenil, se procede al análisis de un conjunto de libros, reunidos bajo la denominación de "El Laberinto". Son cinco obras que integran un "ciclo" desarrollado alrededor de la casa. Estas narrativas siguen, de manera fundamental y en cierta medida, una particular fórmula de ficción celebrada por colecciones como las que firmó Enid Blyton en los años 30 del siglo XX y que continúan siendo reeditadas y comercializadas globalmente en la actualidad. Las novelas juveniles de Ana Teresa Pereira, sin embargo, destacan no solo por la fuerte presencia del misterio y la indagación, sino también por la densidad simbólica de ciertos espacios, por ejemplo la casa, así como por las resonancias o alusiones intertextuales/ culturales que proporcionan el contacto con autores, extractos de textos, títulos de películas, entre otros. 
Palabras clave: narrativa juvenil; ficción de fórmulas; Ana Teresa Pereira; espacio; hogar; simbología; intertextualidad.

\begin{abstract}
Aiming at situate Ana Teresa Pereira, recognized/awarded author in the field of literature usually named canonical or for adults, in the context of contemporary writing preferably dedicated to the youth reader, we proceed to an analysis of a set of books, gathered under the name of "The Labyrinth ". There are five books that incorporate a "cycle" developed around the houses. These narratives follow, in elementary and in some extent, a particular formula fiction made famous by collections such as those by Enid Blyton in the 30s of the twentieth century and still currently being re-edited and globally commercialized. However, youth novels by Ana Teresa Pereira singularize themselves not only by the strong presence of mystery and inquiry, but also by the symbolic density of certain places, such as home, for example, as well as the echoes or intertextual/ cultural allusions which provide contact with authors, textual extracts, film titles, among others.
\end{abstract}

Keywords: narrative for young readers; formula fiction; Ana Teresa Pereira; space; house; symbolism; intertextuality.

"Há casas que têm alma e têm o direito de continuar a existir." (Pereira, 1991c, p. 66)

"No fundo de todos nós há a imagem de uma casa, que existiu ou não na nossa infância. Voltamos lá de vez em quando: nos sonhos nocturnos, nas fantasias diurnas, quando lemos Enid Blyton." (Pereira, 2011, p. 50)

\title{
1.INTRODUÇÃO
}

Entendida como um subsistema em crescimento (Silva, s./d.) e embora o seu estatuto no seio do sistema literário continue ainda a ser problematizado, a literatura juvenil tem vindo a abrir-se a um conjunto mais abrangente de leitores, facto que se deve "por um lado, ao desejo de uma legitimação que de outra forma se torna problemática e, por outro, ao crescente enriquecimento e complexidade dos mecanismos da diegese" (Silva, s./d.). Além disso, concomitante a uma tendência de escrita do género "formula fiction", sobretudo na vertente de livros de aventura, mistério e indagação, muitas vezes, combinada com uma feição didáctica ou informativa, observa-se uma considerável renovação, abertura ou ampliação temática (Blockeel, 2001), substantivada na ficcionalização de tópicos como as relações familiares (abordadas, por exemplo, na perspectiva do adolescente), migração, conflitos sociais, doença, entre outros.

É, porém, comum enunciar-se como uma das fragilidades da literatura juvenil portuguesa o facto de não se operar uma renovação, expansão e consolidação da escrita e da edição de obras no domínio em pauta. Com efeito, depois de 1979, marco histórico no âmbito em questão, pela publicação do romance juvenil Rosa, Minha irmã Rosa, de Alice Vieira (Lisboa, 1943), e mesmo tendo em conta a extensa e reconhecida série de mais de 30 romances já assinados pela referida autora, facto ao qual se acresce, ainda, a edição de novelas e romances juvenis de António Mota (Baião, 1957) ou Ana Saldanha (Porto, 1959), bem como o sucesso de colecções como "O Clube das Chaves"1, de Maria Teresa Maia Gonzalez (Coimbra, 1958) e Maria do Rosário Pedreira (Lisboa, 1959), ou “Triângulo Jota"², de Álvaro Magalhães (Porto, 1951), a verdade é que parece notar-se uma escassez de escritores, de jovens escritores, diríamos mesmo, dedicados à criação 
literária preferencialmente destinada ao público juvenil. Uma ressalva, porém, para registar o facto significativo de, na última década do presente século, se observar o aparecimento de um grupo de jovens autores e da edição de um conjunto de obras juvenis, aliás, muito bem recebidas. Fazem parte deste conjunto Afonso Cruz (Figueira da Foz, 1971), Ana Pessoa (Lisboa, 1982), Carla Maia de Almeida (Matosinhos, 1969) ou David Machado (Lisboa, 1978), todos com romances juvenis de qualidade firmada.

Não surpreende, porém ou ainda assim -porque nos referimos, em todo o caso, a um número restrito de novas vozes-, que alguns autores habitualmente "situados" no domínio da literatura dita consagrada ou canónica, muitos já premiados, tenham pontualmente enveredado pela escrita que tem no jovem o seu potencial destinatário. Referimo-nos, por exemplo, a João Aguiar (1943-2010), com a série "O Bando dos Quatro", Hélia Correia (Lisboa, 1949), com os títulos da colecção Mopsos - O Pequeno Grego (iniciada em 2004), ou, muito particularmente, Ana Teresa Pereira, autora sobre a qual centraremos a nossa atenção neste breve ensaio.

\section{O LUGAR DE ANA TERESA PEREIRA NA LITERATURA JUVENIL PORTUGUESA}

A discrição e a distância (pluralmente entendida) são talvez as características que melhor definem o percurso literário da escritora madeirense Ana Teresa Pereira (Funchal, 1958). Com uma extensa obra narrativa que conta com mais de quarenta títulos, iniciada em Matar a Imagem (1989) e que tem também como títulos, por exemplo, publicados em 2013, As Longas Tardes de Chuva em Nova Orleães (2013) e A Porta Secreta (2013), ou, ainda, A Estalagem do Nevoeiro (2014), A Casa das Sombras e outras Histórias (2015), Karen (2016), O Atelier da Noite (2020) ou Como se o mundo existisse (2021), entre outros, Ana Teresa Pereira tem sido reconhecida quer com a atribuição de prémios diversos (como, logo em 1989, o Prémio Caminho da Literatura Policial, com o seu título inaugural ou, em 2012, o Prémio de Romance e Novela da APE, com a obra O Lago), quer academicamente, em teses/dissertações de mestrado e doutoramento ${ }^{3}$.

Se a insularidade distingue a sua biografia ou geografia vivencial, ela poderá também ser antevista como um dos "traços" da colecção "Labirinto" ou um dos elementos intrínsecos às narrativas juvenis que constituem o corpus da presente abordagem. É, com efeito, se lida/o metaforicamente, uma insularidade ou um ilhamento pressentida/o no aparecimento pontual de cinco títulos preferencialmente destinados aos mais jovens num conjunto extenso de narrativas para leitores adultos.

E, a este título, importa talvez dar conta do facto destas obras virem na esteira de várias outras colecções que surgem em Portugal, no início da década de 80 do século XX. Aquela cujo sucesso editorial assinalamos como ostensivamente "explosivo" foi, sem dúvida, a série "Uma Aventura...", da dupla Ana Maria Magalhães e Isabel Alçada, composta por dezenas de narrativas que vieram a impulsionar de forma determinante a publicação de outros títulos na mesma linha. A propósito deste fenómeno editorial situado no âmbito da literatura juvenil ${ }^{4}$, escreve José António Gomes:

Descoberto o filão, autores e editores apressam-se a publicar, em colecções novas, inúmeras glosas da clássica estrutura triádica Mistério-Aventura-Solução, expressa em meia dúzia de "emocionantes" situações do tipo policial, vividas por grupos de adolescentes ou pré- adolescentes, por vezes acolitados por um 
simpático animal (...). Neste domínio,a Caminho - editora da colecção “Uma Aventura..." - bate todos os recordes. (Gomes, 1991, p. 21)

Os cinco livros que Ana Teresa Pereira dirigiu aos leitores mais jovens, a saber A Casa dos Penhascos (1991) (1), A Casa da Areia (1991) (2), A Casa dos Pássaros (1991) (3), A Casa das Sombras (1991) (4) e A Casa do Nevoeiro (1992) (5) (Editorial Caminho), vindos a lume, entre 1991 e 1992, também com a chancela da Caminho, parecem, pois, ter nascido no contexto enunciado e criados, talvez, a convite ${ }^{5}$.

Sobre esta colecção e acerca do fenómeno a que aludimos, José António Gomes regista, ainda, em Para uma História da Literatura Portuguesa para a Infância e a Juventude:

\footnotetext{
Seria excessivo enumerar aqui as várias colecções deste tipo de literatura de grande consumo, destinada a pré-adolescentes, cujos autores procuraram, a partir de finais dos anos oitenta, aproveitar a onda de sucesso desencadeada pelos livros de Magalhães e Alçada. Destacaremos apenas ${ }^{6}[. .$.$] as histórias de ambiente insular$ madeirense (com curiosas referências ao universo da tradição literária), de Ana Teresa Pereira, na colecção "Labirinto" [...]. (Gomes, 1997, p. 66).
}

Trata-se, com efeito, de uma colecção que poderá integrar a "categoria" das narrativas "de aventuras" ou/e também de "mistério e indagação", cinco volumes que possuem os jovens como leitores implícitos e aos quais a autora junta, em finais de 2013, a novela A Porta Secreta (Relógio d' Água), com o mesmo destinatário extratextual e traços narratológicos similares, ainda que situada fora da referida série. Uma nota, ainda, para assinalar o facto de, em 2009, ter sido dado à estampa, na colecção "Universos Mágicos" da Relógio d'Água, o volume As Duas Casas, obra composta por "A Casa das Sombras" e "A Casa do Nevoeiro", narrativas que constituem uma reedição revista e ligeiramente alterada ${ }^{7}$ dos dois últimos números da série em análise neste breve estudo.

Uma revisitação das cinco obras da colecção "A Casa..." torna evidente, desde logo, além de uma estrutura externa rigorosamente igual (doze capítulos) e de uma extensão muito semelhante, uma assinalável replicação de um padrão de escrita -e até de edição- previsível ou de uma "formula fiction" ao jeito Blytoniano ${ }^{8}$. Além disso, o design/o layout dos cinco volumes obedece a um interessante padrão visual e comercial, evidenciando opções verbo-icónicas intencionalmente comerciais. Note-se, por exemplo, que a capa de cada um dos volumes ostenta a recriação visual da autoria do ilustrador José Miguel Ribeiro (Amadora, 1966) de um momento de tensão/de perigo ou de um momento diegético crucial. Já no que diz respeito à contracapa, constata-se o registo de um breve peritexto no qual se deixa em suspenso aquilo que irá acontecer na narrativa guardada em cada volume, além de um apontamento ilustrativo, de índole catafórica, correspondente ao grupo de jovens que protagonizará a acção.

O legado Blytoniano, e precisando melhor, pode ser antevisto no facto, por exemplo, destas novelas não deixarem de ter como personagens cinco heróis, quatro adolescentes (os irmãos funchalenses David e Cristina, a prima Mónica, que vem do continente passar férias, e o amigo João de Porto Moniz) e um cão (Charlie), um grupo que desvenda mistérios por vários locais da ilha da Madeira, cenário singular onde decorre a acção de todas as "narrativas de aventuras" (Blockeel, 2001, p. 78). À espacialidade relativamente concentrada aduz-se uma temporalidade que poderemos apelidar de esquemática, na medida em que cada "episódio", correspondente a cada volume da série, decorre com um ano de intervalo entre si e todos no período de férias escolares. A própria arquitectura textual revela-se arquetípica e comum às cinco narrativas que possuem como núcleos diegéticos fundamentais: a) um mistério ou uma suspeita; b) a tentativa 
de descoberta ou a investigação; c) uma situação de perigo/ risco ou um ponto culminante; e, finalmente, d) o desenlace positivo ou bem sucedido. Os acontecimentos sucedem-se, portanto, num ritmo ascendente e utilizando- se o "suspense" como elemento intensificador, até a um desfecho feliz. 0 conflito soluciona-se e o relato/a narrativa, construído/a a partir de diálogos simples e vivos que se sobrepõem a breves segmentos descritivos, em muitos casos, notoriamente sensoriais, apela à atenção do leitor também pela linguagem limpa, corrente e sóbria, e pelo tom coloquial, em suma, por um "estilo cuidado e despojado [...] sem padrões convencionais" (Blockeel, 2001, p. 79).

\subsection{A casa nas novelas juvenis da colecção "Labirinto"}

Revistas sucinta e genericamente as cinco narrativas em causa, interessa-nos sobretudo, no contexto de análise inerente a este estudo, reflectir acerca da relevância da categoria do espaço, em particular quando materializado ou coincidente com a casa. Na verdade, o espaço distingue-se como categoria narrativa alicerçante nos textos em apreço, como uma categoria "detentora de inegáveis potencialidades de representação semântica" (Reis e Lopes, 1996, p. 139) ou um "indispensável elemento estrutural do mundo narrado" (Silva, 1990, p. 602).

A leitura ou a abordagem do espaço nas novelas em análise pode ser encetada não apenas a partir das dicotomias macro versus micro e exterior versus interior, mas também da ideia de afunilamento, por exemplo. É, assim, possível situar a acção num espaço físico geograficamente situável e com correspondência empírica ou histórico- factual, um cenário macro/mais vasto ou geral, a ilha da Madeira; depois, em cinco outros, mais circunscritos, toponimicamente verosímeis e identificáveis, que servem de cenário ao conjunto das narrativas -Porto Moniz, Porto Santo, Madalena do Mar, Jardim da Serra e Paul do Mar-; e, ainda, finalmente, nas cinco casas de férias, todas diferentes, todas elas antigas, de aparência mais ou menos abandonada, situadas em locais isolados ou retirados do bulício urbano e rodeadas de vegetação abundante, para onde se desloca o grupo que protagoniza a acção: "Mónica pensou mais uma vez que era divertido aquele sistema de conhecer casas diferentes, em lugares diferentes. [...] Mas era um local belíssimo. As camélias eram enormes, com troncos grossos e inúmeras flores rosa e brancas que se espalhavam pelo chão" (Pereira, 1991d, p. 20, 22).

Este último espaço, mais restrito e substantivado logo na (re)incidência titular do vocábulo "casa" nos volumes da série em pauta, bem como nas diversas inscrições peritextuais, localizadas na contracapa de cada volume, todas elas iniciadas com o mesmo lexema/sema, associadas naturalmente à centralidade (e peculiar representação) de que se reveste ao longo das novelas em questão (bem como na generalidade dos títulos assinados pela autora ${ }^{9}$ ), convida a uma interpretação atenta.

Com efeito, a casa, cosmos tratado ficcionalmente ${ }^{10}$, com assiduidade, tanto na literatura canónica ou consagrada ${ }^{11}$, como na literatura de potencial recepção infantil ${ }^{12}$, e ao qual se encontra subjacente uma importante configuração simbólica, figura diversamente nas narrativas juvenis de Ana Teresa Pereira. Note-se que simbolicamente "a casa é o símbolo do centro vital dos homens [...] Para a psicologia profunda, a casa é um símbolo importante, por exemplo, no sonho [...] o acontece "na casa" acontece dentro de nós. Frequentemente nós mesmos somos a casa." (Biedermann, 1994, p. 75-76). Além disso, "A casa significa o ser interior, segundo Bachelard; os seus andares, a cave e o sótão simbolizam os diversos estados da alma. A cave corresponde ao inconsciente; o sótão, à elevação espiritual. [...] A casa é também um símbolo feminino, no sentido de refúgio, de mãe, 
de proteção, de seio maternal." (Chevalier e Gheerbrant, 1994, p. 166). Na ficção juvenil de Ana Teresa Pereira, a casa representa um espaço onde cabem labirintos e passagens secretas, um local de (re)encontro e protecção, enfim, uma espécie de abrigo que, descoberto nas férias, acolhe os heróis e lhes serve, por vezes, de estímulo à curiosidade. Simultaneamente, para a personagem adulta que com eles ou com as figuras mais novas "habita”, Carla, escritora de romances policiais ${ }^{13}$, funciona como espaço de recolhimento/isolamento propício à criação literária. Assume, assim, cada casa como o seu espaço, como local onde "faz sentido", onde, como regista Bachelard, "a imaginação aumenta os valores da realidade" (Bachelard, 2003, p. 23) e onde existe um abrigo para "o devaneio", se protege o sonhador", porque "a casa permite sonhar em paz" (Bachelard, 2003, p. 26) .

Nestes textos, não são raras as alusões à casa como uma concha ou um búzio:

"Era como se a tia [Carla] só gostasse de viajar com uma concha.Tinha de ter uma casa, de estar rodeada de livros..." (Pereira, 1991d, p. 20); "A casa desenrolava-se como uma imensa concha vazia. Como um búzio no qual se ouvia por vezes o som do mar." (Pereira, 1991d, p. 25). Estas identificações possuem relevantes implicações simbólicas, merecedoras de uma referência, ainda que muito breve. Um dos sentidos simbólicos atribuídos à concha e ao búzio consiste na fecundidade, prosperidade e sorte (Chevalier e Gheerbrant, 1994, p. 217), bem como nas ideias de "[as] grandes viagens, [as] grandes evoluções, interiores e exteriores" (Chevalier e Gheerbrant, 1994, p. 135), linhas ideotemáticas que não podem ser excluídas da leitura/interpretação que levarmos a cabo dos textos de Ana Teresa Pereira.

Albergando todas as acções narradas, a casa é, pois, vivida e entendida intensamente pelos protagonistas. Mesmo a primeira visão, ostensivamente subjectiva, que desta têm, bem como a percepção da sua arquitectura interior e exterior deixam transparecer um fascínio e um envolvimento evidentes. Quartos vazios ou fechados, compartimentos muito escuros ou sombrios, corredores, escadas que não dão para parte nenhuma ou que desembocam na água, túneis que principiam em casa e terminam na aldeia ${ }^{14}$ ou passagens secretas entre paredes ${ }^{15}$ caracterizam as casas destas narrativas, adensando o seu constante clima de mistério e de segredo e alimentando a imaginação das personagens. A este título, vale a pena reler os seguintes segmentos textuais:

A casa era imensa e sombria. Parecia deslizar um pouco para um dos lados, como se fosse inclinada. Tinha à frente um alpendre com arcos. A pintura das paredes estava carcomida pelo tempo. [...] Passaram a tarde a explorar a casa. [...] Havia alguns quartos fechados, que deviam ser os aposentos dos guardas, ao fundo de um corredor. Escadas que aparentemente não conduziam a lugar nenhum. Uma grande biblioteca com inúmeros volumes antigos. Muito pouca luz. (Pereira, 1991d, p. 25).

Era alta e,como as outras ao longo da rua, não tinha qualquer patio ou alpendre.A porta ficava praticamente ao nível do solo e as janelas, fechadas, davam-lhe um ar adormecido. (...) A casa estava escura e muito limpa.A mobília era extremamente simples mas não desprovida de conforto.Eraumacasacomoelesgostavam,cheiadecantoseescadas.(Pereira,1992,p.32-33).

Assumimos, por conseguinte, a perspectiva de Coelho e Santos, quando registam:

A casa representa aí espaço de duplicidade, simultaneamente familiar e estranho, onde nos podemos perder como um labirinto, encobrindo um alçapão, uma passagem e espaços secretos que alojam uma atividade paralela, escondendo algo ou alguém à espera de ser descoberto. (Coelho e Santos, 2014, p. 4).

De facto, apontamentos variados impõem a (omni)presença da casa não apenas no cenário físico/geográfico no qual se movem as figuras das narrativas, mas também nos seus imaginários pessoais ou na sua interioridade. Releia-se, por exemplo, o incipit de A Casa das Sombras, quarto volume da colecção: "Cristina começou a desenhar uma casa na margem do caderno. / Uma torre, 
uma janela marcada com um X, uma parede de pedra. [...] Daí a pouco desenhou outra casa. Esta era alta e com inúmeras janelas, mas sem qualquer porta possível" (Pereira, 1991d, p. 7-8).

E a sua relevância é igualmente deixada transparecer nas citações ou alusões literárias que pontuam as narrativas em questão e que as dotam de um importante aporte intertextual. No terceiro volume da colecção, A Casa dos Pássaros, por exemplo, inclui-se o seguinte poema de Carlos de Oliveira (1921-1981), inserido em Trabalho Poético:

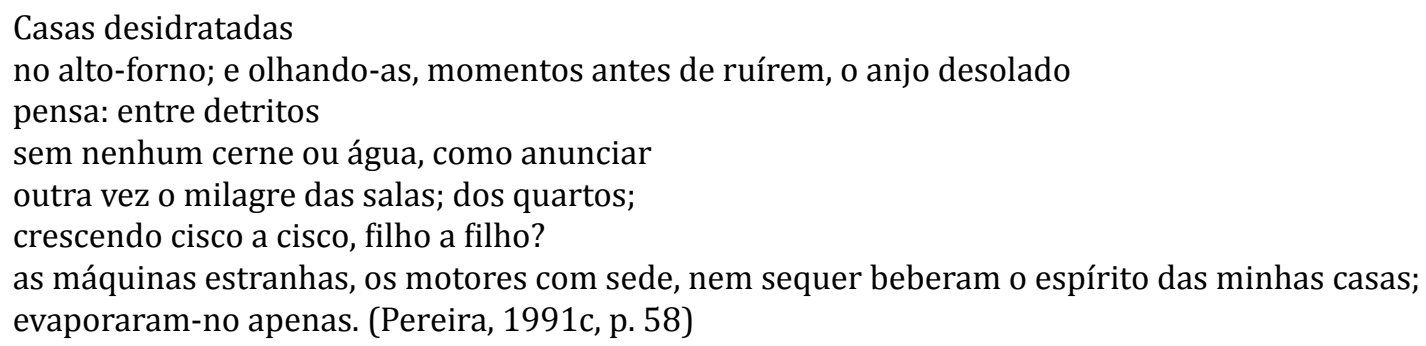

E, no último exemplar da série, A Casa do Nevoeiro, Mónica cita o clássico Peter Pan: “ - A ilha também andava à procura deles - leu em voz alta. E, mais à frente: - Agora a casa estava verdadeiramente acabada. Restava bater à porta" (Pereira, 1992, p. 16).

Acresce, ainda, que as referências assíduas à leitura, à literatura e a alguns dos seus modelos actanciais, por exemplo, bem como a alusão a autores ou a títulos de obras, sugerindo a intenção autoral de celebrar um significativo jogo intelectual com o leitor, configuram uma importante estratégia radicada na metaficção, facto que, por exemplo, Blockeel (2001, p. 79) entende como um fenómeno original e pouco frequente em séries juvenis contemporânea da que integra os volumes em foco. Vejase, por exemplo, em A Casa dos Pássaros, o final do capítulo VIII, no qual João afirma “- Vocês lêem demasiados romances policiais [...]" e Cristina acaba por contestar, exaltada, “- Tu irritas-me [...] Pensas que és um detective dos livros, daqueles que guardam a solução até ao último instante?" (Pereira, 1991c, p. 55).

\section{CONSIDERAÇÕES FINAIS}

No estudo que, agora, fechamos, procurámos, além de situar sucintamente a escrita de Ana Teresa Pereira (também) no subsistema literário particular coincidente com a literatura juvenil, perscrutar analiticamente algumas das isotopias da escrita da autora em pauta, focando a nossa atenção nos espaços e, muito particularmente na casa, que, em última instância, parece ser ficcionalizada ou imaginada pela autora em pauta como um "ser concentrado" que leva a uma consciência de centralidade" (Bachelard, 2003, p. 36).

Com efeito, e retomando a dicotomia de Nikolajeva (1996) relativa à funcionalidade do espaço como elemento narratológico, ou seja, a distinção entre "backdrop setting" ("which may be basically anywhere and anytime") e "integral setting" ("that are an essential part of the plot"), observa-se que o espaço, em geral, e a casa, em particular, nas narrativas revisitadas, se identificam com a segunda acepção, na medida em que se revestem de diversas funções, designadamente emoldurar a actuação das personagens, criar uma atmosfera adequada ou facilitadora da acção dos actantes, auxiliar a sua caracterização e revelar a sua atitude mental, entre outras (Nikolajeva, 1996, p. 24).A mesma investigadora, problematizando o significado da casa, identifica-a com um cronótopo que, não raras vezes, sustém a acção (Nikolajeva, 2005). 
Assim, nas novelas analisadas, as personagens e os lugares, como a ilha, a casa, o jardim ou a biblioteca, constituem unidades narrativas que, aliadas à ficcionalização de temáticas como a infância/adolescência, a família, o medo, o amor, a natureza e a arte (pintura, cinema ${ }^{16}$ e, muito especialmente, literatura, frequentemente de matriz anglo- saxónica), compõem um universo literário com sintomas textuais e com propostas de significação que reclamam uma desconstrução de processos/mecanismos como a intertextualidade, a metaficcionalidade, a auto-reflexividade ou o hibridismo.Trata-se, na verdade, de um conjunto coeso de tessituras ficcionais, quase sempre polifónicas, de filiação tendencialmente pós-moderna, coincidentes com tendências literárias contemporâneas não apenas no domínio da escrita potencial recepção juvenil, mas também para adultos (Silva, 2012), facto que permite inclusivamente aproximar aos textos revistos da escrita ambivalente, de destinatário dual ou "crossover" (Beckett, 1999; Falconer, 2009).

Desenvolvida em torno de um conjunto mais ou menos restrito de topoi e motivemas, facto que denuncia uma personalidade literária ou uma escrita que pode efectivamente ser apelidada de obsessiva (Sardo, 2013), as narrativas de Ana Teresa Pereira, em particular as que vocacionou para os mais jovens, tecem-se de ingredientes simultaneamente sofisticados, que, mesmo desafiando culturalmente, se apresentam próximos do leitor, proporcionando-lhe, como poucas, o contacto com uma "hipermemória literária - ou melhor, com um imaginário fornecido pela literatura e pelo cinema [...]" (Guerreiro, 2012, s/p) que, em muito e informal ou discretamente, poderá contribuir para a consolidação da sua cultura artística/estética.

\section{Referências bibliográficas}

Almeida, C. M. (2011). Onde Moram as Casas. Caminho. [Ilustrações de Alexandre Esgaio]

Bachelard, G. (2003) A Poética do Espaço. Martins Fontes.

Basílio, R. (2005). "Falemos de casas" Em torno do poema "Prefácio" de Herberto Helder. Textos e Pretextos (As Casas), 6, 8-15.

Beckett, S. L. (Ed.) (1999). Transcending Boundaries.Writing for a Dual Audience of Children and Adults. Garland Publishing.

Belo, R. (2000). Todos os Poemas. Assírio \& Alvim.

Biedermann, H. (1994). Dicionário Ilustrado de Símbolos. Melhoramentos.

Blockeel, F. (2001). Literatura Juvenil Portuguesa Contemporânea: Identidade e Alteridade. Caminho.

Bruno, P. e Geneste, P. (2008). Le roman pour la jeunesse. Em D. Escarpit, La littérature de jeunesse. Itinéraires d'hier à aujourd'hui (pp. 390-446). Éditions Magnard.

Chevalier, J. e Gheerbrant, A. (1994). Dicionário dos Símbolos. Teorema.

Coelho, L. M. e Santos, T. P. (2014). A formula fiction segundo Ana Teresa Pereira. Reflexos, 2.

Falconer, R. (2009). Cross-reading and Crossover Books. Em N. J.Watson e J. Maybin, (Ed.)., Children's Literature: Approaches and Territories (pp. 366-379). Palgrave Macmillan in association with The Open University.

Gomes, J. A. (1991). Literatura para Crianças e Jovens. Alguns Percursos. Caminho.

Gomes, J.A. (1997). Para uma História da Literatura Portuguesa para a Infância e a Juventude. Ministério da Cultura/Instituto Português do Livro e das Bibliotecas.

Guerreiro, A. (2012). A escritora que na semana passada viu o seu último livro premiado pela APE não é facilmente classificável. Atual, 2088. 
Jorge, L. N. (1993). Poesia 1960-1989. Assírio \& Alvim.

Nikolajeva, M. (1996). Introduction to theTheory of Children's Literature.Tallin Pedagogical University.

Nikolajeva, M. (2005). Aesthetic Approaches to Children's Literature.The Scarecrow Press.

Pereira, A. T. (1991a). A Casa dos Penhascos. Editorial Caminho.

Pereira, A. T. (1991b). A Casa da Areia. Editorial Caminho.

Pereira, A. T. (1991c). A Casa dos Pássaros. Editorial Caminho.

Pereira, A. T. (1991d). A Casa das Sombras. Editorial Caminho.

Pereira, A. T. (1992). A Casa do Nevoeiro. Editorial Caminho.

Pereira, A. T. (2009). As Duas Casas. Relógio d' Água.

Pereira, A. T. (2011). A Escada para o Sotão. Islenha, 48, 45-50.

Pereira, A. T. (2013). A Porta Secreta. Relógio d' Água.

Pina, M. A. (2011). Como se Desenha Uma Casa. Assírio \& Alvim.

Reis, C. e Lopes, A. C. M. (1996). Dicionário de Narratologia. Almedina.

Santos, I. F. (2005). Pelas veredas da infância: o regresso a casa num poema de Manuel António Pina. Textos e Pretextos (As Casas), 6, 78-89.

Sardo, A. (2013). A Audácia de ser Diferente: A Escrita Obsessiva de Ana Teresa Pereira [Dissertação de Doutoramento em Literatura]. Universidade de Aveiro.

Silva, M. M. C.T. da (2012). Uma Escrita de Transição: contributos para uma reflexão sobre literatura juvenil. Em B.-A. Roig Rechou, I. Soto López e M. Neira Rodríguez (coord.), A Narrativa Xuvenil a Debate (2000-2011) (pp. 13-36). Edicións Xerais de Galicia.

Silva, M. M. C. T. da (s./d.). Literatura em crescimento. O lugar problemático da literatura juvenil no sistema literário. http://www.casadaleitura.org

Silva,V. A. e (1990). Teoria da Literatura [8 $8^{\mathrm{a}}$ ed.]. Almedina.

Notas

1 Esta colecção é composta por 21 livros, publicados entre 1990 e 2000.

2 Constam desta série 20 volumes, editados entre 1989 e 2014.

3 Apenas um exemplo: Sardo, Anabela Oliveira da Naia (2013). A Audácia de Ser Diferente: A Escrita Obsessiva de Ana Teresa Pereira. Dissertação de Doutoramento em Literatura Portuguesa apresentada à Universidade de Aveiro, em Dezembro de 2013 (texto policopiado).

4 Segundo Bruno e Geneste (2008), "Dans un premier temps, le lecteur est perçu comme un apprendi au goût "barbare" qu'on séduit par les procédés les plus simples [...] avant que, dans un deuxième temps, les collections se destinent à l'initiation ao littéraire" (Bruno e Geneste, 2008, p. 398).

5 Ver “[...] provavelmente uma encomenda em jeito de desafio à então jovem autora." (Coelho e Santos, 2014, p. 1).

6 José António Gomes, a par da colecção de Ana Teresa Pereira, menciona, por exemplo, “1001 detectives”, de Carlos Correia, Maria Alberta Menéres e Natércia Rocha, e “O Clube das Chaves”, de Maria Teresa Maia Gonzalez e Maria do Rosário Pedreira.

7 Esta informação não se encontra registada nesta publicação. Num contexto distinto do da presente análise, valeria a pena analisar em detalhe as alterações de que foram alvo os textos originais publicados nos primeiros anos de 90 do século passado.

8 Sobre esta questão, ver o estudo pormenorizado de Coelho e Santos (2014). Lembramos, ainda, que, em 2013, Alice Vieira publicou O Mundo de Enid Blyton (Texto Editora), obra fundamental para a dilucidação da biografia da autora em questão e para a problematização da sua influência na literatura portuguesa, por exemplo.

9 Ver A Cidade Fantasma (1993) ou Num Lugar Solitário (1996), apenas para citar dois exemplos. 
10 Os versos "As casas fluem de noite/sob a maré dos rios // São altamente mais dóceis / que as crianças / Dentro de estuque se fecham / pensativas", de Luíza Neto Jorge (Jorge, 1993, p. 93) e, muito especialmente, "As casas que eu fazia em pequeno / onde estarei eu hoje em pequeno?” (Belo, 2000, p. 370), de Ruy Belo, promovem uma inevitável referência à relevância/lugar da casa na infância ou no imaginário infantil. Pensemos, por exemplo, nas "casinhas de bonecas", nas "casas nas árvores" ou no jogo de faz-de-conta que consiste em "brincar às casinhas" e a estes junte-se, ainda, a conhecida canção "Era uma casa muito engraçada. Não tinha tecto, não tinha nada...".

11 A casa representa um dos núcleos semânticos seminais, por exemplo, da escrita poética de Manuel António Pina. Inês Fonseca Santos, por exemplo, di-lo, com a propriedade e a sensibilidade que a caracterizam, em "Pelas ve- redas da infância: o regresso a casa num poema de Manuel António Pina", ensaio no qual se refere à casa como centro unificador do eu, escrevendo: "E é deste pressentimento da infância enquanto origem que decorre a consideração da casa como o microcosmos arquetípico capaz de acolher os momentos felizes do eu" (SANTOS, 2005, p. 84).

12 Neste domínio, sobressai esse perturbante conto que é A Casinha de Chocolate (ou Hansel e Gretel), com a assinatura dos irmãos Grimm -um dos exemplos indiscutíveis da pervivência da literatura de origem tradicional oral na literatura preferencialmente dirigida ao leitor infanto-juvenil- e, também, a novela Uma Casa Muito Doce, de Ana Saldanha (Caminho, 2003), por defluir, intertextualmente, do referido conto. Ainda vocacionados para um destina- tário extratextual juvenil, uma referência breve a "A Casa do Mar", conto datado de 1970 e patente em Histórias da Terra e do Mar, de Sophia de Mello Breyner Andresen (1984), exemplo da fusão do sujeito com as coisas.

13 Não deixa de ser curiosa esta nota que poderemos situar no domínio da auto-reflexividade, uma vez que as novelas da série "Labirinto" se centram em "aventuras de notação policial” (Silva, 2012, p. 27).

14 Ver A Casa dos Pássaros.

15 A Casa do Nevoeiro.

16 Ver "- Parece um filme de terror." e "- Tem o clima de um filme de Hitchcock - comentou David" (Pereira, 1991c, p. 20-21); “- Parece a ponte do Indiana Jones” (Pereira, 1991d, p. 31); “-Podemos ir ver o Hook, de Steven Spielberg - sugeriu David - É baseado no Peter Pan.” (Pereira, 1992, p. 13).

Citar: Silva, Sara Raquel Duarte Reis da (2021). "Labirintos e casas, portas e segredos: análise do espaço nas novelas juvenis de Ana Teresa Pereira”. Elos. Revista de Literatura Infantil e Xuvenil, 8, “Notas”, 1-10. ISSN 2386-7620. DOI http://dx.doi.org/10.15304/elos.8.7624 